\title{
Isoniazid and rifampicin inhibit allosterically heme binding to albumin and peroxynitrite isomerization by heme-albumin
}

\author{
Paolo Ascenzi • Alessandro Bolli • Alessandra di Masi • \\ Grazia R. Tundo · Gabriella Fanali • \\ Massimo Coletta $\cdot$ Mauro Fasano
}

Received: 28 April 2010/Accepted: 27 August 2010/Published online: 25 September 2010

(c) SBIC 2010

\begin{abstract}
Human serum heme-albumin (HSA-heme) displays globin-like properties. Here, the allosteric inhibition of ferric heme [heme-Fe(III)] binding to human serum albumin (HSA) and of ferric HSA-heme [HSA-heme-Fe(III)]-mediated peroxynitrite isomerization by isoniazid and rifampicin is reported. Moreover, the allosteric inhibition of isoniazid and rifampicin binding to HSA by heme-Fe(III) has been investigated. Data were obtained at $\mathrm{pH} 7.2$ and $20.0^{\circ} \mathrm{C}$. The affinity of isoniazid and rifampicin for HSA $\left[K_{0}=(3.9 \pm 0.4) \times 10^{-4}\right.$ and $(1.3 \pm 0.1) \times 10^{-5} \mathrm{M}$, respectively] decreases by about 1 order of magnitude upon heme-Fe(III) binding to HSA $\left[K_{\mathrm{h}}=(4.3 \pm 0.4) \times 10^{-3}\right.$ and $(1.2 \pm 0.1) \times 10^{-4} \mathrm{M}$, respectively]. As expected, the heme-Fe(III) affinity for HSA $\left[H_{0}=(1.9 \pm 0.2) \times\right.$ $10^{-8} \mathrm{M}$ ] decreases by about 1 order of magnitude in the
\end{abstract}

Electronic supplementary material The online version of this article (doi:10.1007/s00775-010-0706-2) contains supplementary material, which is available to authorized users.

\footnotetext{
P. Ascenzi $(\bowtie) \cdot$ A. Bolli $\cdot$ A. di Masi

Department of Biology and Interdepartmental

Laboratory for Electron Microscopy,

University Roma Tre,

Viale Guglielmo Marconi 446,

00146 Rome, Italy

e-mail: ascenzi@uniroma3.it

P. Ascenzi

National Institute for Infectious Diseases I.R.C.C.S.

'Lazzaro Spallanzani',

Via Portuense 292,

00149 Rome, Italy

G. R. Tundo $\cdot$ M. Coletta

Department of Experimental Medicine

and Biochemical Sciences,

University of Roma 'Tor Vergata',

Via Montpellier 1, 00133 Rome, Italy
}

presence of saturating amounts of isoniazid and rifampicin $\left[H_{\mathrm{d}}=(2.1 \pm 0.2) \times 10^{-7} \mathrm{M}\right]$. In the absence and presence of $\mathrm{CO}_{2}$, the values of the second-order rate constant $\left(l_{\text {on }}\right)$ for peroxynitrite isomerization by $\mathrm{HSA}-\mathrm{heme}-\mathrm{Fe}(\mathrm{III})$ are $4.1 \times 10^{5}$ and $4.3 \times 10^{5} \mathrm{M}^{-1} \mathrm{~s}^{-1}$, respectively. Moreover, isoniazid and rifampicin inhibit dose-dependently peroxynitrite isomerization by HSA-heme-Fe(III) in the absence and presence of $\mathrm{CO}_{2}$. Accordingly, isoniazid and rifampicin impair in a dose-dependent fashion the HSA-heme-Fe(III)based protection of free L-tyrosine against peroxynitritemediated nitration. This behavior has been ascribed to the pivotal role of Tyr150, a residue that either provides a polar environment in Sudlow's site I (i.e., the binding pocket of isoniazid and rifampicin) or protrudes into the heme-Fe(III) cleft, depending on ligand binding to Sudlow's site I or to the FA1 pocket, respectively. These results highlight the role of drugs in modulating heme-Fe(III) binding to HSA and HSA-heme-Fe(III) reactivity.

\author{
G. R. Tundo · M. Coletta \\ Interuniversity Consortium for the Research \\ on the Chemistry of Metals in Biological Systems, \\ Via Celso Ulpiani 27, 70126 Bari, Italy \\ G. Fanali $\cdot$ M. Fasano \\ Department of Structural and Functional Biology, \\ Center of Neuroscience, University of Insubria, \\ Via Alberto da Giussano 12, \\ 21052 Busto Arsizio (VA), Italy
}


Keywords Allostery - Ferric human serum hemealbumin · Human serum albumin · Isoniazid · Rifampicin

$\begin{array}{ll}\text { Abbreviations } & \\ \text { FA } & \text { Fatty acid } \\ \text { Heme-Fe(III) } & \text { Ferric heme } \\ \text { HSA } & \begin{array}{l}\text { Human serum albumin } \\ \text { HSA-heme }\end{array} \\ \text { HSAman serum heme-albumin } \\ \text { HSA-heme-Fe(III) } & \begin{array}{l}\text { Ferrous nitrosylated human serum } \\ \text { heme-albumin }\end{array} \\ & \begin{array}{l}\text { Ferric human serum heme- } \\ \text { albumin }\end{array}\end{array}$

\section{Introduction}

Human serum albumin (HSA) is the most abundant protein in plasma and provides a depot and carrier for many compounds. As a consequence, HSA affects the pharmacokinetics of many drugs, holds some ligands in a strained orientation that results in their metabolic modification, and renders potential toxins harmless, transporting them to disposal sites. Moreover, HSA accounts for most of the antioxidant capacity of human serum and displays enzymatic properties [1-9].

HSA is a single nonglycosylated all- $\alpha$-chain protein, constituted by 585 amino acids, containing three homologous domains (labeled I, II, and III). Each domain is made up of two separate subdomains (named A and B) connected by random coils. Interdomain helical regions link subdomain IB to subdomain IIA and subdomain IIB to subdomain IIIA (Fig. 1) (see [2, 8-11]).

The structural organization of HSA provides several ligand binding sites (Fig. 1). HSA displays seven binding clefts hosting chemically diverse ligands including fatty acids (FAs), and are therefore labeled FA1-FA7 (Fig. 1). In particular, FA1 is located within the IB subdomain contacting the IB-IIA polypeptide linker and the long IBIIA transdomain helix; FA2 is located at the interface between subdomains IA, IB, and IIA; FA3 and FA4 together contribute to Sudlow's site II (i.e., the ibuprofen primary site) in subdomain IIIA; FA5 is located within subdomains IIIA and IIIB; FA6 is a solvent-accessible linear slot located at the interface between subdomains IIA and IIB; and FA7 corresponds to Sudlow's site I (i.e., the warfarin binding site) in subdomain IIA. FA2 and FA6 clefts appear to be the secondary binding sites of ibuprofen. Moreover, HSA binds ligands (e.g., thyroxine) in the cleft between domains I and III and the bacterial HSA-binding modules to domain II [7, 9, 10, 12-19].

The FA1 binding site has evolved to selectively bind the ferric heme [heme-Fe(III)] with a high affinity

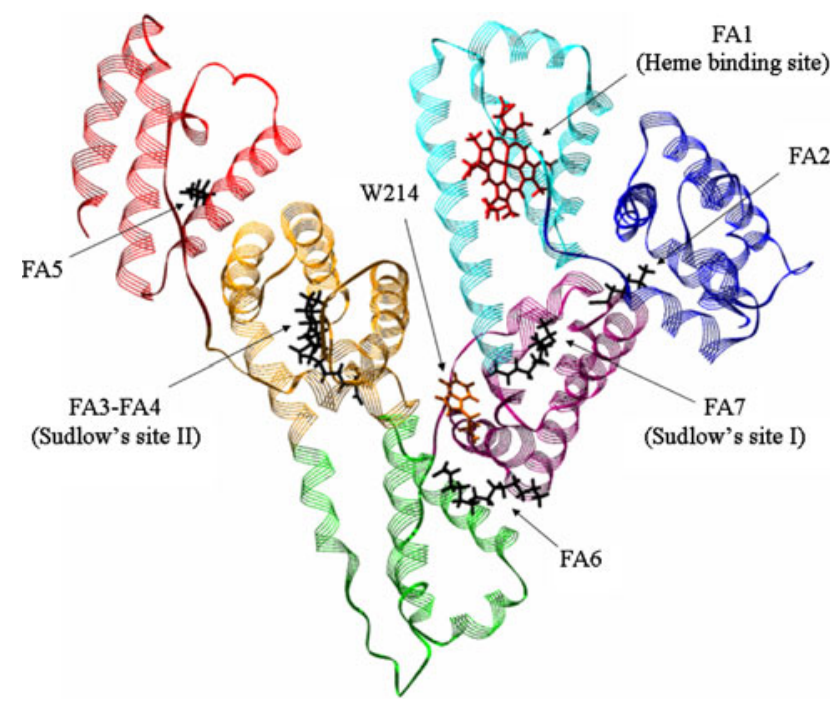

Fig. 1 Three-dimensional structure of human serum albumin (HSA). Subdomains are labeled as follows: blue IA, cyan IB, purple IIA, green IIB, yellow IIIA, and red IIIB. Ligand binding clefts are shown and labeled FA1-FA7; FA1 is occupied by the heme (red sticks), whereas FA2-FA7 are occupied by myristate ions (black sticks). The spectroscopically active Trp214 residue (W214) is rendered in orange sticks and labeled. FA7 corresponds to Sudlow's site I (i.e., the warfarin site). The FA3 and FA4 sites form Sudlow's site II (i.e., the ibuprofen site). Atomic coordinates were taken from Protein Data Bank code 1O9X [78]. For further details, see the text

$\left(H_{0}=1.3 \times 10^{-8} \mathrm{M}\right)$, so HSA participates physiologically to heme scavenging [20-23]. The tetrapyrrole ring is arranged in a D-shaped cavity limited by Tyr138 and Tyr161 residues that provide $\pi-\pi$ stacking interaction with the porphyrin and supply a donor oxygen (from Tyr161) for the heme atom. The heme is secured to HSA by the long IA-IB connecting loop that fits into the cleft opening [9, 24-26]. In turn, heme endows HSA with reactivity and spectroscopic properties similar to those of hemoglobin and myoglobin $[9,12,26-41]$. Remarkably, both heme$\mathrm{Fe}(\mathrm{III})$ binding to HSA and human serum heme-albumin (HSA-heme) reactivity are modulated allosterically $[8,9$, 19, 24, 29, 32-34, 38, 39, 42, 43].

Here, the effect of isoniazid and rifampicin, two widely used antituberculosis drugs [44], on heme-Fe(III) binding to HSA and ferric HSA-heme [HSA-heme-Fe(III)]-mediated peroxynitrite ${ }^{1}$ isomerization is reported. Isoniazid and rifampicin impair heme-Fe(III) binding to HSA and vice versa, according to linked functions [45]. Moreover, isoniazid and rifampicin inhibit dose-dependently peroxynitrite isomerization by HSA-heme-Fe(III), and the HSAheme-Fe(III)-based protection of free L-tyrosine against

\footnotetext{
${ }^{1}$ The recommended IUPAC nomenclature for peroxynitrite is oxoperoxonitrate(1-) and for peroxynitrous acid is hydrogen oxoperoxonitrate. The term "peroxynitrite" is used in the text to refer generically to both $\mathrm{ONOO}^{-}$and its conjugate acid $\mathrm{ONOOH}$ (see $[33,53,59,77])$.
} 
peroxynitrite-mediated nitration. These results highlight the role of drugs in modulating both heme binding to HSA and HSA-heme reactivity.

\section{Materials and methods}

\section{Materials}

Hemin [iron(III) protoporphyrin IX] chloride was purchased from Sigma-Aldrich (St. Louis, MO, USA). The heme$\mathrm{Fe}$ (III) stock solution $\left(5.0 \times 10^{-3} \mathrm{M}\right)$ was prepared by dissolving heme-Fe(III) in $1.0 \times 10^{-2} \mathrm{M} \mathrm{NaOH}$ [46]. The heme-Fe(III) concentration was determined spectrophotometrically at $535 \mathrm{~nm}$ after converting heme-Fe(III) to the heme-Fe(III) bisimidazolate derivative in sodium dodecyl sulfate micelles $\left(\varepsilon_{535 \mathrm{~nm}}=14.5 \times 10^{3} \mathrm{M}^{-1} \mathrm{~cm}^{-1}\right)$ [47].

HSA (purity $96 \%$ or better, essentially FA free) was obtained from Sigma-Aldrich. The HSA concentration was determined spectrophotometrically at $280 \mathrm{~nm}\left(\varepsilon_{280} \mathrm{~nm}=\right.$ $3.82 \times 10^{4} \mathrm{M}^{-1} \mathrm{~cm}^{-1}$ ) [46]. The HSA stock solution $\left(2.0 \times 10^{-4} \mathrm{M}\right)$ was prepared by diluting the hydrophobic ligand-free HSA solution with $2.0 \times 10^{-2} \mathrm{M}$ sodium phosphate buffer, at $\mathrm{pH} 7.2$ and $20.0^{\circ} \mathrm{C}$. The HSA-heme$\mathrm{Fe}(\mathrm{III})$ stock solution $\left(2.0 \times 10^{-4} \mathrm{M}\right)$ was prepared by adding a $0.8 \mathrm{M}$ defect of the heme-Fe(III) stock solution to the HSA solution $\left(\mathrm{pH} 7.2,1.0 \times 10^{-1} \mathrm{M}\right.$ sodium phosphate buffer) at $20.0{ }^{\circ} \mathrm{C}$ [33-36, 39-41, 46, 48]. The final HSA and HSA-heme-Fe(III) concentrations ranged between $1.0 \times 10^{-8}$ and $5.0 \times 10^{-6} \mathrm{M}$.

Isoniazid and rifampicin (Fig. S1) were purchased from Sigma-Aldrich. The isoniazid stock solution $(2.0 \times$ $\left.10^{-1} \mathrm{M}\right)$ was prepared by dissolving the drug in $95 \%$ water-5.0\% methanol (v/v). The rifampicin stock solution $\left(2.0 \times 10^{-2} \mathrm{M}\right)$ was prepared by dissolving the drug in methanol [49]. The final isoniazid and rifampicin concentrations ranged between $1.0 \times 10^{-5}$ and $2.0 \times 10^{-2} \mathrm{M}$ and between $1.0 \times 10^{-6}$ and $2.0 \times 10^{-3} \mathrm{M}$, respectively.

Peroxynitrite was synthesized from $\mathrm{KO}_{2}$ and $\mathrm{NO}$ and from $\mathrm{HNO}_{2}$ and $\mathrm{H}_{2} \mathrm{O}_{2}$ and was stored in small aliquots at $-80.0^{\circ} \mathrm{C}$ $[50,51]$. The peroxynitrite stock solution $\left(2.0 \times 10^{-3} \mathrm{M}\right)$ was diluted immediately before use with degassed $5.0 \times 10^{-2} \mathrm{M} \mathrm{NaOH}$ to reach the desired concentration [33, 48, 52-55]. Nitrate and nitrite contaminations were in the ranges $0-7 \%$ and $8-19 \%$ of the peroxynitrite concentration, respectively (see "Methods"). The concentration of peroxynitrite was determined spectrophotometrically prior to each experiment by measuring the absorbance at $302 \mathrm{~nm}$ $\left(\varepsilon_{302 \mathrm{~nm}}=1.705 \times 10^{3} \mathrm{M}^{-1} \mathrm{~cm}^{-1}\right)[50,51,55,56]$.

Experiments in the presence of $\mathrm{CO}_{2}$ were carried out by adding to the protein solutions the required amount of a $5.0 \times 10^{-1} \mathrm{M} \mathrm{NaHCO} 3$ solution. After the addition of bicarbonate, the protein solutions were allowed to equilibrate for at least $5 \mathrm{~min}$ [33, 48, 52-55]. For the experiments carried out in the absence of $\mathrm{CO}_{2}$, all solutions were thoroughly degassed and kept under nitrogen or helium [33, 48, 52-55].

All the other chemicals were obtained from SigmaAldrich and Merck (Darmstadt, Germany). All products were of analytical or reagent grade and were used without further purification.

Methods

\section{Isoniazid and rifampicin binding to HSA}

Values of the dissociation equilibrium constant for isoniazid and rifampicin binding to HSA (i.e., $K_{0}$ ) were obtained spectrofluorimetrically at $\mathrm{pH} 7.2\left(1.0 \times 10^{-1} \mathrm{M}\right.$ phosphate buffer) and $20.0^{\circ} \mathrm{C}$. The intrinsic tryptophan fluorescence of HSA in the absence and presence of isoniazid and rifampicin was recorded between 290 and $700 \mathrm{~nm}$; the excitation wavelength was $280 \mathrm{~nm}$. The excitation and emission slit widths were $5 \mathrm{~nm}$. Small aliquots of either isoniazid $\left(2.0 \times 10^{-1} \mathrm{M}\right)$ or rifampicin $\left(2.0 \times 10^{-2} \mathrm{M}\right)$ stock solutions were added to the $\operatorname{HSA}\left(5.0 \times 10^{-6} \mathrm{M}\right)$ solution, and the drug-dependent changes of the intrinsic fluorescence of HSA were recorded after incubation for $10 \mathrm{~min}$ after each addition. The intrinsic fluorescence of both drugs was recorded between 290 and $700 \mathrm{~nm}$ (the excitation wavelength was $280 \mathrm{~nm}$ ) to evaluate the interference with the intrinsic tryptophan fluorescence of $\operatorname{HSA}[6,21,22,57,58]$. No intrinsic fluorescence of isoniazid and rifampicin between 290 and $700 \mathrm{~nm}$ (the excitation wavelength was $280 \mathrm{~nm}$ ) was observed. Test measurements performed after $2 \mathrm{~h}$ of HSA-drug incubation excluded slow kinetic effects.

Isoniazid and rifampicin binding to HSA was analyzed by plotting the molar fraction of the drug-HSA complex (i.e., $Y$ ) as a function of the free drug concentration. Data were analyzed according to Eq. $1[6,21,22,57,58]$ :

$Y=\Delta F / \Delta F_{\max }=[\operatorname{drug}] /\left(K_{0}+[\operatorname{drug}]\right)$

where $\Delta F$ is the fluorescence change at a given drug concentration, and $\Delta F_{\max }$ is the fluorescence change at the saturating drug concentration.

\section{Isoniazid and rifampicin binding to HSA-heme-Fe(III)}

Values of the dissociation equilibrium constant for isoniazid and rifampicin binding to HSA-heme-Fe(III) (i.e., $K_{\mathrm{h}}$ ) were obtained spectrophotometrically at pH $7.2\left(1.0 \times 10^{-1} \mathrm{M}\right.$ phosphate buffer) and $20.0^{\circ} \mathrm{C}$. Heme-Fe(III)-based drugdependent absorbance changes were recorded between 350 and $450 \mathrm{~nm}$. Small aliquots of either isoniazid $\left(2.0 \times 10^{-1} \mathrm{M}\right)$ or rifampicin $\left(2.0 \times 10^{-2} \mathrm{M}\right)$ stock solutions were added to the HSA-heme-Fe(III) $\left(5.0 \times 10^{-6} \mathrm{M}\right)$ 
solution and the drug-dependent absorbance changes of HSA-heme-Fe(III) were recorded after incubation for $10 \mathrm{~min}$ after each addition [21, 22]. Test measurements performed after $2 \mathrm{~h}$ of HSA-heme-Fe(III)-drug incubation excluded slow kinetic effects.

Isoniazid and rifampicin binding to HSA-heme-Fe(III) was analyzed by plotting the molar fraction of the drugHSA-heme-Fe(III) complex (i.e., $Y$ ) as a function of the free drug concentration. Data were analyzed according to Eq. 2 [21, 22]:

$Y=\Delta A / \Delta A_{\max }=[\mathrm{drug}] /\left(K_{\mathrm{h}}+[\mathrm{drug}]\right)$

where $\Delta A$ is the absorbance change at a given drug concentration, and $\Delta A_{\max }$ is the absorbance change at the saturating drug concentration.

\section{Heme-Fe(III) binding to HSA and HSA-drug complexes}

Values of the dissociation equilibrium constant for heme$\mathrm{Fe}(\mathrm{III})$ binding to HSA in the absence and presence of isoniazid and rifampicin (i.e., $H_{0}$ and $H_{\mathrm{d}}$, respectively) were obtained spectrophotometrically at pH $7.2\left(1.0 \times 10^{-1} \mathrm{M}\right.$ phosphate buffer) and $20.0^{\circ} \mathrm{C}$. Heme-Fe(III)-dependent absorbance changes were recorded between 350 and $450 \mathrm{~nm}$. Small aliquots of the HSA $\left(2.0 \times 10^{-4} \mathrm{M}\right)$ stock solution were added to the heme-Fe(III) $\left(5.0 \times 10^{-7} \mathrm{M}\right)$ solution in the absence and presence of isoniazid $\left(3.0 \times 10^{-5}-3.0 \times 10^{-2} \mathrm{M}\right)$ and rifampicin $\left(3.0 \times 10^{-6}\right.$ $\left.3.0 \times 10^{-3} \mathrm{M}\right)$. The heme-Fe(III)-dependent absorbance changes accompanying HSA-heme-Fe(III) formation were recorded after incubation for $10 \mathrm{~min}$ after each addition [21, 22]. Test measurements performed after $2 \mathrm{~h}$ of HSA-heme$\mathrm{Fe}(\mathrm{III})$ and HSA-heme-Fe(III)-drug incubation excluded slow kinetic effects.

Heme-Fe(III) binding to HSA in the absence and presence of isoniazid and rifampicin was analyzed by plotting the molar fraction of HSA-heme-Fe(III) (i.e., $Y$ ) as a function of the HSA concentration. Data were analyzed according to Eq. 3 [21, 22]:

$Y=\Delta A / \Delta A_{\max }=[\mathrm{HSA}] /(H+[\mathrm{HSA}])$

where $H$ corresponds to either $H_{0}$ or $H_{\mathrm{d}}$.

The dependence of the dissociation equilibrium constant $H$ for heme-Fe(III) binding to HSA as a function of the isoniazid or rifampicin concentration was analyzed according to Eq. $4[21,22,45]$ : $\log H=\log H_{\mathrm{d}}^{-1}+\log \left\{\left([\mathrm{drug}]+K_{\mathrm{h}}\right) /\left([\mathrm{drug}]+K_{0}\right)\right\}$

Peroxynitrite isomerization in the absence and presence of $\mathrm{HSA}$-heme- $\mathrm{Fe}(\mathrm{III}), \mathrm{CO}_{2}$, isoniazid, and rifampicin

The kinetics of peroxynitrite isomerization in the absence and presence of $\mathrm{HSA}$-heme-Fe(III), $\mathrm{CO}_{2}$, isoniazid, and rifampicin was recorded with SMF-20 and SMF-400 rapidmixing stopped-flow apparatus (Bio-Logic, Claix, France). The light path of the observation cuvette was $10 \mathrm{~mm}$, and the dead time was $1.4 \mathrm{~ms}$. The kinetics was monitored at $302 \mathrm{~nm}$, the characteristic absorbance maximum of peroxynitrite $\left(\varepsilon_{302 \mathrm{~nm}}=1.705 \times 10^{3} \mathrm{M}^{-1} \mathrm{~cm}^{-1}\right)[50,51,55$, 56]. Kinetic data were obtained in the absence and presence of HSA-heme-Fe(III) (final concentration $5.0 \times 10^{-6}$ $\left.4.0 \times 10^{-5} \mathrm{M}\right), \mathrm{CO}_{2}$ (final concentration $1.2 \times 10^{-3} \mathrm{M}$ ) isoniazid (final concentration $2.0 \times 10^{-4}-1.0 \times 10^{-2} \mathrm{M}$ ), and rifampicin (final concentration $4.0 \times 10^{-5}-5.0 \times$ $10^{-4} \mathrm{M}$ ) by rapid mixing of the HSA-heme-Fe(III) buffered solution with the peroxynitrite solution (final concentration $\left.2.5 \times 10^{-4} \mathrm{M}\right)$. The kinetics was obtained at $\mathrm{pH} 7.2$ $\left(1.0 \times 10^{-1} \mathrm{M}\right.$ phosphate buffer $)$ and $20.0^{\circ} \mathrm{C}$; no gaseous phase was present.

The kinetics of peroxynitrite isomerization by HSAheme-Fe(III) in the absence and presence of $\mathrm{CO}_{2}$, isoniazid, and rifampicin was analyzed in the framework of the minimum reaction mechanism (Scheme 1) [33, 53, 59].

Values of the pseudo-first-order rate constant for HSAheme-Fe(III)-mediated peroxynitrite isomerization (i.e., $l_{\text {obs }}$ ) were determined in the absence and presence of $\mathrm{CO}_{2}$, isoniazid, and rifampicin, at $\mathrm{pH} 7.2$ and $20.0{ }^{\circ} \mathrm{C}$, from the analysis of the time-dependent absorbance decrease at $302 \mathrm{~nm}$, according to Eq. 5 [33, 53, 59]:

$[\text { peroxynitrite }]_{t}=[\text { peroxynitrite }]_{i} \times \mathrm{e}^{-l_{\text {obs }} \times t}$

Values of the second-order rate constant for HSA-heme$\mathrm{Fe}$ (III)-mediated peroxynitrite isomerization (i.e., $l_{\text {on }}$ ) and of the first-order rate constant for peroxynitrite isomerization in the absence of HSA-heme-Fe(III) (i.e., $l_{0}$ ) were determined in the absence and presence of $\mathrm{CO}_{2}$, isoniazid, and rifampicin, at $\mathrm{pH} 7.2$ and $20.0{ }^{\circ} \mathrm{C}$, from the linear dependence of $l_{\text {obs }}$ on the HSA-heme-Fe(III) concentration according to Eq. $6[33,53,59,60]$ :

$l_{\text {obs }}=l_{\text {on }} \times[$ HSA-heme-Fe(III) $]+l_{0}$

Values of $l_{0}$ for peroxynitrite isomerization in the absence of HSA-heme-Fe(III) were also determined in the
Scheme 1 Minimum reaction mechanism for peroxynitrite isomerization by HSA-heme$\mathrm{Fe}(\mathrm{III})$

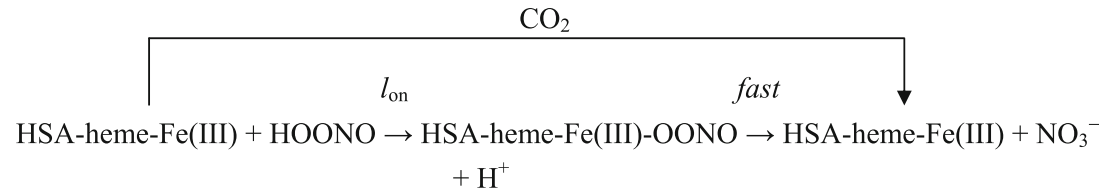

$+\mathrm{H}^{+}$ 
absence and presence of $\mathrm{CO}_{2}$, isoniazid, and rifampicin, at pH 7.2 and $20.0{ }^{\circ} \mathrm{C}$, from the analysis of the timedependent absorbance decrease at $302 \mathrm{~nm}$, according to Eq. $7[33,53,59]$ :

$[\text { peroxynitrite }]_{t}=[\text { peroxynitrite }]_{i} \times \mathrm{e}^{-l_{0} \times t}$

Values of $K_{\mathrm{h}}$ were determined, at $\mathrm{pH} 7.2$ and $20.0^{\circ} \mathrm{C}$, from the dependence of $l_{\text {on }}$ on the drug concentration (i.e., isoniazid concentration ranging between $2.0 \times 10^{-4}$ and $1.0 \times 10^{-2} \mathrm{M}$, and rifampicin concentration ranging between $4.0 \times 10^{-5}$ and $5.0 \times 10^{-4} \mathrm{M}$ ). The effect of the drug concentration on $l_{\text {on }}$ was analyzed according to Eq. $8[33,53,59,60]$ :

$l_{\text {on }}=l_{\text {on (top })}-\left(\left(l_{\text {on }(\text { top })} \times[\operatorname{drug}]\right) /\left(K_{\mathrm{h}}+[\operatorname{drug}]\right)\right)$

where $l_{\text {on(top) }}$ represents the value of $l_{\text {on }}$ under conditions where $[$ drug $]=0$ (i.e., $l_{\text {on(top) }}=l_{\text {on }}$ ).

\section{Determination of $\mathrm{NO}_{2}{ }^{-}$and $\mathrm{NO}_{3}{ }^{-}$concentration}

$\mathrm{NO}_{2}{ }^{-}$and $\mathrm{NO}_{3}{ }^{-}$analysis was carried out spectrophotometrically at $543 \mathrm{~nm}$ by using the Griess reagent and $\mathrm{VCl}_{3}$ to catalyze the conversion of $\mathrm{NO}_{3}{ }^{-}$to $\mathrm{NO}_{2}^{-}$, as described previously $[33,59,61,62]$. Calibration curves were obtained by measuring four to eight standard sodium nitrite and sodium nitrate solutions in $1.0 \times 10^{-1} \mathrm{M}$ phosphate buffer, $\mathrm{pH} 7.2$ and $20.0^{\circ} \mathrm{C}$. The samples were prepared by mixing $500 \mu \mathrm{L}$ of a HSA-heme-Fe(III) solution (initial concentration $1.0 \times 10^{-4} \mathrm{M}$ in $2.0 \times 10^{-1} \mathrm{M}$ phosphate buffer, $\mathrm{pH}$ 7.2) with $500 \mu \mathrm{L}$ of a peroxynitrite solution (initial concentration $4.0 \times 10^{-4} \mathrm{M}$ in $0.01 \mathrm{M} \mathrm{NaOH}$ ) with vortexing, at $20.0^{\circ} \mathrm{C}$, in the absence and presence of $\mathrm{CO}_{2}\left(1.2 \times 10^{-3} \mathrm{M}\right)$, isoniazid $\left(1.0 \times 10^{-2} \mathrm{M}\right)$, and rifampicin $\left(5.0 \times 10^{-4} \mathrm{M}\right)$. The reaction mixture was analyzed within approximately $10 \mathrm{~min}$.

\section{Peroxynitrite-mediated formation of nitro-L-tyrosine in the absence and presence of HSA-heme-Fe(III), $\mathrm{CO}_{2}$, isoniazid, and rifampicin}

The reaction of peroxynitrite with free L-tyrosine was carried out at $\mathrm{pH} 7.2$, at both 20.0 and $37.0^{\circ} \mathrm{C}$, by adding $0.2 \mathrm{~mL}$ of an alkaline $\left(1.0 \times 10^{-2} \mathrm{M} \mathrm{NaOH}\right)$ solution of peroxynitrite $\left(2.0 \times 10^{-3} \mathrm{M}\right)$ to $1.8 \mathrm{~mL}$ of a buffered $\left(1.0 \times 10^{-1} \mathrm{M}\right.$ phosphate buffer $)$ solution of L-tyrosine (final concentration $1.0 \times 10^{-4} \mathrm{M}$ ) in the absence and presence of HSA-heme-Fe(III) (final concentration $5.0 \times$ $\left.10^{-6}-5.0 \times 10^{-5} \mathrm{M}\right), \quad \mathrm{CO}_{2}$ (final concentration $1.2 \times$ $10^{-3} \mathrm{M}$ ), isoniazid (final concentration $2.0 \times 10^{-4}$ $-1.0 \times 10^{-2} \mathrm{M}$ ), and rifampicin (final concentration $4.0 \times 10^{-5}-5.0 \times 10^{-4} \mathrm{M}$ ). The amount of nitro-L-tyrosine was determined by high-performance liquid chromatography, as previously reported [33].
Values of $K_{\mathrm{h}}$ were determined from the dependence on the drug concentration of the relative yield of nitro-Ltyrosine formed from the reaction of peroxynitrite with free L-tyrosine in the absence and presence of HSA-heme$\mathrm{Fe}(\mathrm{III})$, i.e., $Y=$ [yield with added HSA-heme-Fe(III)/ yield with no HSA-heme-Fe(III)] $\times 100$ [33]. The effect of the isoniazid and rifampicin concentration on $Y$ was analyzed according to Eq. 9 [33]:

$Y=\left(((100-R) \times[\operatorname{drug}]) /\left(K_{\mathrm{h}}+[\operatorname{drug}]\right)\right)+R$

where $R$ corresponds to $Y$ in the absence of the drug.

\section{Data analysis}

Kinetic and thermodynamic data were analyzed using the MATLAB program (The MathWorks, Natick, MA, USA). The results are given as mean values of at least four experiments plus or minus the corresponding standard deviation.

\section{Docking analysis}

Simulated automatic flexible ligand docking to HSA was performed by using Autodock 4.0 and the graphical user interface AutoDockTools [63-65]. The structure of HSAwarfarin was downloaded from the Protein Data Bank (code 2BXD) [7]. The isoniazid structure bound to cytosolic soybean ascorbate peroxidase was downloaded from the Protein Data Bank (code 2VCF) [66]. The rifampicin geometry in complex with Thermus aquaticus core RNA polymerase was downloaded from the Protein Data Bank (code 1I6V) [67]. Single bonds were allowed to rotate freely during the Monte Carlo simulated annealing procedure. The analysis of the conformational space was restricted to a cubic box of $60 \AA$ edge centered on the coordinates of warfarin. Monte Carlo simulated annealing was performed by starting from a temperature of $900 \mathrm{~K}$ with a relative cooling factor of 0.95 per cycle to reach the temperature of $5 \mathrm{~K}$ in 100 cycles [63-65].

\section{Results}

Isoniazid and rifampicin binding to HSA

Isoniazid and rifampicin binding to HSA was investigated by analyzing the perturbation of the intrinsic tryptophan fluorescence of HSA that arises from the unique tryptophan residue located near Sudlow's site I in subdomain IIA, at position 214 (Fig. 1). Isoniazid induces a perturbation of the intrinsic tryptophan fluorescence of HSA similar to that induced by rifampicin [58] (data not shown), as already reported for the binding of several drugs, including warfarin, to Sudlow's site I $[2,6,8,9,21,22,57,68,69]$. 
Therefore, the perturbation of the tryptophan fluorescence of HSA appears to be essentially drug-independent $[2,6,8$, $9,21,22,57,68]$.

Figure 2 shows the binding isotherms for isoniazid and rifampicin association to $\mathrm{HSA}$ at $\mathrm{pH} 7.2$ and $20.0{ }^{\circ} \mathrm{C}$. The analysis of the data given in Fig. 2, according to Eq. 1, allowed the determination of $K_{0}$ values for isoniazid and rifampicin binding to HSA $\left[(3.9 \pm 0.4) \times 10^{-4}\right.$ and $(1.3 \pm 0.1) \times 10^{-5} \mathrm{M}$, respectively]. The Hill coefficient (n) for isoniazid and rifampicin binding to HSA is $1.00 \pm 0.02$, indicating that drug binding to HSA is a noncooperative event.

\section{Isoniazid and rifampicin binding to HSA-heme-Fe(III)}

Isoniazid and rifampicin binding to HSA-heme-Fe(III) was investigated by analyzing the perturbation of the electronic
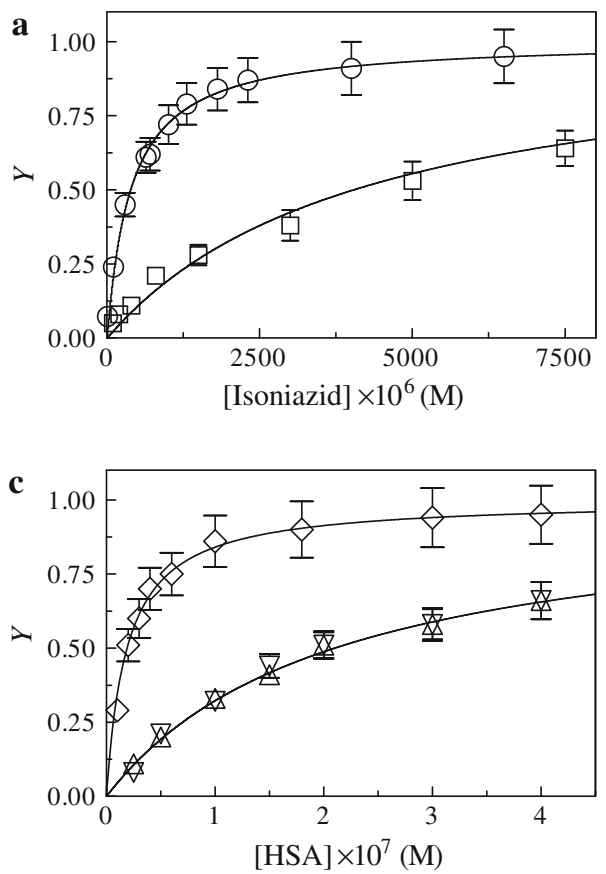

Fig. 2 Isoniazid and rifampicin binding to HSA and ferric human serum heme-albumin [HSA-heme-Fe(III)]. a Thermodynamics of isoniazid binding to HSA (circles) and HSA-heme-Fe(III) (squares). The lines were calculated according to Eqs. 1 and 2 by nonlinear regression curve fitting with $K_{0}=(3.9 \pm 0.4) \times 10^{-4} \mathrm{M}$ and $K_{\mathrm{h}}=(4.3 \pm 0.4) \times 10^{-3} \mathrm{M}$. The isoniazid concentration corresponds to that of the free ligand. The HSA and HSA-heme-Fe(III) concentrations were $5.0 \times 10^{-6} \mathrm{M}$. b Thermodynamics of rifampicin binding to HSA (circles) and HSA-heme-Fe(III) (squares). The lines were calculated according to Eqs. 1 and 2 by nonlinear regression curve fitting with $K_{0}=(1.3 \pm 0.1) \times 10^{-5} \mathrm{M}$ and $K_{\mathrm{h}}=(1.2 \pm$ $0.1) \times 10^{-4} \mathrm{M}$. The rifampicin concentration corresponds to that of the free ligand. The HSA and HSA-heme-Fe(III) concentrations were $5.0 \times 10^{-6} \mathrm{M}$. c Thermodynamics of ferric heme [heme-Fe(III)] binding to HSA in the absence (diamonds) and presence of isoniazid (upward triangles) and rifampicin (downward triangles). The lines were calculated according to Eq. 3 by nonlinear regression curve fitting with $H_{0}=(1.9 \pm 0.2) \times 10^{-8} \mathrm{M}$ and $H_{\mathrm{d}}=(2.1 \pm$ absorption spectra of HSA-heme-Fe(III). Note that Sudlow's site I and the heme cleft (Fig. 1) are spectroscopically and structurally linked $[8,9,21,22,34]$. Isoniazid and rifampicin induce a very similar decrease in the absorption coefficient and a superimposable blueshift of the maximum of the electronic absorption spectrum of HSA-heme-Fe(III) (data not shown), as already reported for drug binding to Sudlow's site I (e.g., warfarin). Therefore, the perturbation of the electronic absorption spectra of HSA-heme-Fe(III) appears to be essentially drug-independent $[8,9,21,22,34,69]$.

Figure 2 shows the binding isotherms for isoniazid and rifampicin association to HSA-heme-Fe(III) at $\mathrm{pH} 7.2$ and $20.0{ }^{\circ} \mathrm{C}$. The analysis of the data given in Fig. 2, according to Eq. 2, allowed the determination of $K_{\mathrm{h}}$ values for isoniazid and rifampicin binding to HSA-heme-Fe(III) $[(4.3 \pm$ $0.4) \times 10^{-3}$ and $(1.2 \pm 0.1) \times 10^{-4} \mathrm{M}$, respectively]
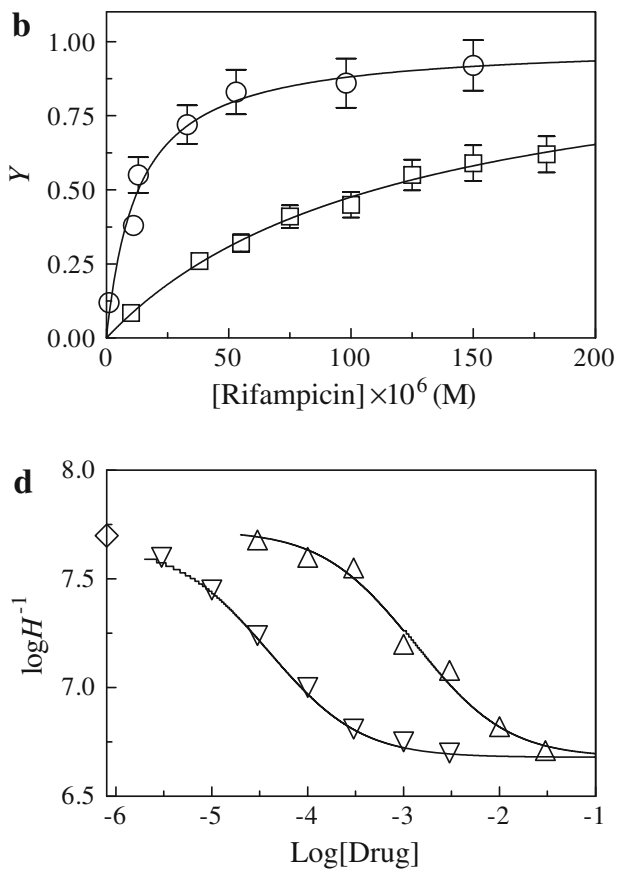

$0.2) \times 10^{-7} \mathrm{M}$. The HSA concentration corresponds to that of the free ligand; the heme-Fe(III) concentration was $5.0 \times 10^{-7} \mathrm{M}$, the isoniazid concentration was $3.0 \times 10^{-2} \mathrm{M}$, and the rifampicin concentration was $3.0 \times 10^{-3} \mathrm{M}$. d Dependence of the apparent association equilibrium constant $H$ for heme-Fe(III) binding to HSA on the isoniazid (upward triangles) and rifampicin (downward triangles) concentrations. The diamond indicates the $H_{0}^{-1}$ value for HSA binding to heme-Fe(III) in the absence of drugs. The lines were calculated according to Eq. 4 by nonlinear regression curve fitting with the following sets of parameters: isoniazid $-H_{\mathrm{d}}^{-1}=(4.8 \pm 0.5) \times$ $10^{6} \mathrm{M}^{-1}, \quad K_{0}=(3.9 \pm 0.4) \times 10^{-4} \mathrm{M}, \quad$ and $\quad K_{\mathrm{h}}=(4.3 \pm 0.4) \times$ $10^{-3} \mathrm{M} ; \quad$ and rifampicin- $H_{\mathrm{d}}^{-1}=(4.8 \pm 0.5) \times 10^{6} \mathrm{M}^{-1}, \quad K_{0}=$ $(1.3 \pm 0.1) \times 10^{-5} \mathrm{M}$, and $K_{\mathrm{h}}=(1.2 \pm 0.1) \times 10^{-4} \mathrm{M}$. The isoniazid and rifampicin concentrations correspond to the concentration of the free ligand. Where not shown, the standard deviation is smaller than the symbol. Data were obtained at $\mathrm{pH} 7.2$ and $20.0^{\circ} \mathrm{C}$. For further details, see the text 
The Hill coefficient $(n)$ for isoniazid and rifampicin binding to HSA-heme-Fe(III) is $1.00 \pm 0.03$, indicating that drug binding to HSA-heme-Fe(III) is a noncooperative event.

As already reported for the association of several drugs to Sudlow's site I, heme-Fe(III) inhibits isoniazid and rifampicin binding to HSA, $K_{0}$ being lower than $K_{\mathrm{h}}$ by about 1 order of magnitude (Fig. 2). Notably, this phenomenon is essentially drug-independent $[8,9,21,22,26,34,38,69]$.

\section{Heme-Fe(III) binding to HSA and HSA-drug} complexes

Heme-Fe(III) binding to HSA in the absence and presence of isoniazid and rifampicin was investigated by analyzing the perturbation of the electronic absorption spectrum of heme-Fe(III). The absorption coefficient and the maximum of the electronic absorption spectra of HSA-heme-Fe(III)isoniazid and HSA-heme-Fe(III)-rifampicin complexes are lower and blueshifted with respect to those of the drug-free HSA-heme-Fe(III). Furthermore, the electronic absorption spectra of HSA-heme-Fe(III)-drug complexes appear to be drug-independent $[8,9,21,22,34]$.

Figure 2 shows the binding isotherms for heme-Fe(III) association to HSA in the absence and presence of isoniazid and rifampicin at $\mathrm{pH} 7.2$ and $20.0^{\circ} \mathrm{C}$. The analysis of data given in Fig. 2, according to Eq. 3, allowed the determination of $H_{0}$ and $H_{\mathrm{d}}$ values for heme-Fe(III) binding to HSA in the absence and presence of the drugs, respectively. The value of $H_{0}$ for heme-Fe(III) binding to HSA $\left(1.9 \pm 0.2 \times 10^{-8} \mathrm{M}\right)$ agrees with the values reported in the literature $[2,8,21,22$, 34]. Isoniazid and rifampicin inhibit heme-Fe(III) binding to HSA, $H_{0}$ being lower than $H_{\mathrm{d}}$ by about 1 order of magnitude (Fig. 2). The values of $H_{\mathrm{d}}$ for heme-Fe(III) binding to HSA in the presence of saturating levels of isoniazid and rifampicin $\left[H_{\mathrm{d}}=(2.1 \pm 0.2) \times 10^{-7} \mathrm{M}\right.$; present study], as well as of several drugs all binding to Sudlow's site I (e.g., warfarin), appear to be essentially drug-independent $[8,9,21,22,26,34$, $38,69]$. Both in the absence and in the presence of isoniazid and rifampicin, the Hill coefficient $(n)$ for heme-Fe(III) binding to HSA is $1.00 \pm 0.03$, indicating that drug binding to HSA-heme-Fe(III) is a noncooperative event.

According to linked functions [45], the values of $H_{\mathrm{d}}, K_{0}$, and $K_{\mathrm{h}}$ obtained experimentally (Fig. 2) are in excellent agreement with those calculated according to Eq. 4 (Fig. 2), thus giving confidence that the assumptions underlying Eq. 4 are correct.

Effect of isoniazid and rifampicin on HSA-heme-Fe(III)-mediated peroxynitrite isomerization

The kinetics of peroxynitrite isomerization in the absence and presence of HSA-heme-Fe(III), $\mathrm{CO}_{2}$, isoniazid, and rifampicin was recorded by single-wavelength stoppedflow apparatus. Under all the experimental conditions, a decrease of the absorbance at $302 \mathrm{~nm}$ was observed, as previously reported [33]. The kinetics of peroxynitrite isomerization was fitted to a single-exponential decay for more than $95 \%$ of its course (see Eq. 5). According to the literature [33], this indicates that no intermediate species [e.g., HSA-heme-Fe(III)-OONO; see Scheme 1] accumulate(s) in the course of peroxynitrite isomerization. In particular, the formation of the transient HSA-heme$\mathrm{Fe}(\mathrm{III})-\mathrm{OONO}$ species represents the rate-limiting step in catalysis, the conversion of the HSA-heme-Fe(III)-OONO complex to HSA-heme-Fe(III) and $\mathrm{NO}_{3}{ }^{-}$being faster by at least 1 order of magnitude.

In the absence and presence of $\mathrm{CO}_{2}$, isoniazid, and rifampicin, the observed rate constants for HSA-heme$\mathrm{Fe}(\mathrm{III})$-catalyzed isomerization of peroxynitrite (i.e., $l_{\mathrm{obs}}$ ) increase linearly with the HSA-heme-Fe(III) concentration (Fig. S2). The analysis of the data reported in Fig. 3, according to Eq. 6, allowed the determination of the values of the second-order rate constant for peroxynitrite isomerization by HSA-heme-Fe(III) (i.e., $l_{\text {on }}$, corresponding to the slope of the linear plots) and of the first-order rate constant for peroxynitrite isomerization in the absence of HSA-heme-Fe(III) (i.e., $l_{0}$, corresponding to the $y$ intercept of the linear plots). The values of $l_{0}$ obtained according to Eq. 6 are in excellent agreement with those experimentally determined according to Eq. 7 (see Table 1). In the absence of the drugs, the values of $l_{\text {on }}$ and $l_{0}$ for peroxynitrite isomerization in the absence and presence of $\mathrm{CO}_{2}$ are in excellent agreement with those reported in the literature [33].

The values of $l_{\text {on }}$ for HSA-heme-Fe(III)-catalyzed isomerization of peroxynitrite are essentially unaffected by $\mathrm{CO}_{2}$ (Fig. 3, Table 1). In contrast, the value of $l_{0}$ for peroxynitrite isomerization obtained in the presence of $\mathrm{CO}_{2}$ $\left(15.9 \mathrm{~s}^{-1}\right)$ is higher by about 2 orders of magnitude than that obtained in the absence of $\mathrm{CO}_{2}\left(2.8 \times 10^{-1} \mathrm{~s}^{-1}\right)$ (Table 1). The lack of a $\mathrm{CO}_{2}$-linked effect on peroxynitrite isomerization by HSA-heme-Fe(III) is likely related to the fact that peroxynitrite reacts faster with HSA-heme-Fe(III) $\left(l_{\text {on }}=4.1 \times 10^{5}\right.$ and $I_{\text {on }}=4.3 \times 10^{5} \mathrm{M}^{-1} \mathrm{~s}^{-1}$ in the absence and presence of $\mathrm{CO}_{2}$, respectively; Table 1) than with $\mathrm{CO}_{2}\left(l_{\text {on }}=3 \times 10^{4} \mathrm{M}^{-1} \mathrm{~s}^{-1}\right)[55,56,70,71]$.

In the absence and presence of $\mathrm{CO}_{2}$, isoniazid and rifampicin affect dose-dependently the $l_{\mathrm{on}}$ values for HSAheme-Fe(III)-mediated isomerization of peroxynitrite (Fig. 3). Indeed, the values of $l_{\text {on }}$ for HSA-heme-Fe(III)catalyzed isomerization of peroxynitrite decrease from $4.1 \times 10^{5} \mathrm{M}^{-1} \mathrm{~s}^{-1}$ in the absence of drugs and $\mathrm{CO}_{2}$ to $1.3 \times 10^{5} \mathrm{M}^{-1} \mathrm{~s}^{-1}$ at an isoniazid concentration of $1.0 \times$ $10^{-2} \mathrm{M}$, and to $1.1 \times 10^{5} \mathrm{M}^{-1} \mathrm{~s}^{-1}$ at a rifampicin concentration of $5.0 \times 10^{-4} \mathrm{M}$. Moreover, the values of 

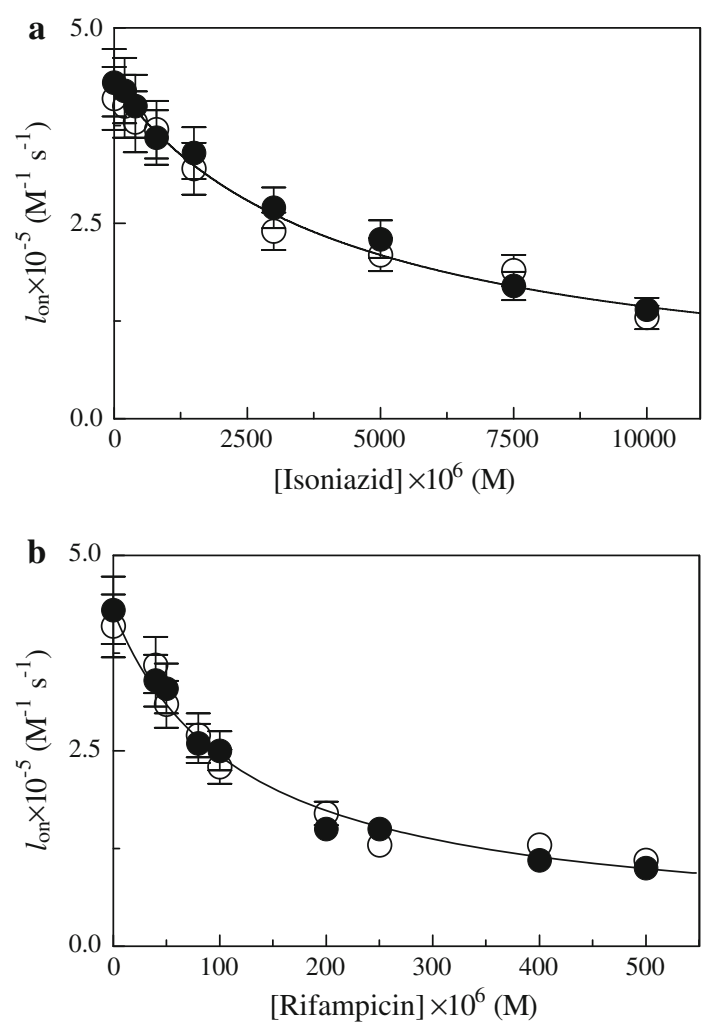

Fig. 3 Inhibition of HSA-heme-Fe(III)-mediated peroxynitrite isomerization by isoniazid (a) and rifampicin (b). Effect of the isoniazid and the rifampicin concentration on the second-order rate constant for HSA-heme-Fe(III)-catalyzed isomerization of peroxynitrite (i.e., $l_{\text {on }}$ ) in the absence (open circles) and presence (filled circles) of $\mathrm{CO}_{2}$. The lines were calculated according to Eq. 8 with the following parameters: isoniazid- $l_{\text {on(top })}=(4.2 \pm 0.3) \times 10^{5} \mathrm{M}^{-1} \mathrm{~s}^{-1}$ and $K_{\mathrm{h}}=(4.3 \pm 0.4) \times 10^{-3} \mathrm{M} ; \quad$ rifampicin- $l_{\text {on(top })}=(4.2 \pm 0.3) \times$ $10^{5} \mathrm{M}^{-1} \mathrm{~s}^{-1}$ and $K_{\mathrm{h}}=(1.2 \pm 0.1) \times 10^{-4} \mathrm{M}$. Where not shown, the standard deviation is smaller than the symbol. Data were obtained at $\mathrm{pH} 7.2$ and $20.0^{\circ} \mathrm{C}$. For details, see the text

$l_{\text {on }}$ decrease from $4.3 \times 10^{5} \mathrm{M}^{-1} \mathrm{~s}^{-1}$ in the absence of drugs and in the presence of $\mathrm{CO}_{2}$ to $1.4 \times 10^{5} \mathrm{M}^{-1} \mathrm{~s}^{-1}$ at an isoniazid concentration of $1.0 \times 10^{-2} \mathrm{M}$, and to $1.0 \times$ $10^{5} \mathrm{M}^{-1} \mathrm{~s}^{-1}$ at a rifampicin concentration of $5.0 \times$ $10^{-4} \mathrm{M}$ (Fig. 3, Table 1). By contrast, the values of $l_{0}$ are unaffected by isoniazid and rifampicin, being only dependent on $\mathrm{CO}_{2}$ (Fig. 3, Table 1).

According to Eq. 8 (Fig. 3), the analysis of the dependence of $l_{\text {on }}$ for HSA-heme-Fe(III)-catalyzed isomerization of peroxynitrite on the isoniazid and rifampicin concentrations allowed the determination of the $\mathrm{CO}_{2}$-independent values of $K_{\mathrm{h}}$ for isoniazid and rifampicin binding to HSA-heme-Fe(III) $\left[(4.3 \pm 0.4) \times 10^{-3}\right.$ and $(1.2 \pm 0.1) \times$ $10^{-4} \mathrm{M}$, respectively]. The Hill coefficient $(n)$ for isoniazid and rifampicin binding to HSA-heme-Fe(III) is $1.00 \pm 0.02$, indicating that drug binding to HSA-heme$\mathrm{Fe}(\mathrm{III})$ is a noncooperative event.

Under conditions where the drug concentration is much greater than $K_{\mathrm{h}}$, HSA-heme-Fe(III) does not catalyze the isomerization of peroxynitrite as observed in the presence of noncatalytic HSA and HSA-heme-Fe(III)-cyanide [33].

Analysis of the nitrogen-containing products of HSA-heme-Fe(III)-mediated peroxynitrite isomerization

According to the literature $[33,53,59]$, the spontaneous isomerization of peroxynitrite yields $74 \pm 5 \% \mathrm{NO}_{3}{ }^{-}$and $24 \pm 4 \% \mathrm{NO}_{2}{ }^{-}$. In the presence of HSA-heme-Fe(III), the $\mathrm{NO}_{3}{ }^{-}$and $\mathrm{NO}_{2}{ }^{-}$yields increase (approximately 90\%) and decrease (approximately 10\%), respectively. The same result has been observed in the presence of HSA-heme$\mathrm{Fe}$ (III) and $\mathrm{CO}_{2}$. Lastly, isoniazid and rifampicin do not significantly affect the $\mathrm{NO}_{3}{ }^{-}$and $\mathrm{NO}_{2}{ }^{-}$yields (Table 2 ).

Isoniazid and rifampicin inhibit

HSA-heme-Fe(III)-based protection of free

L-tyrosine against peroxynitrite-mediated nitration

HSA-heme-Fe(III) protects dose-dependently free L-tyrosine against peroxynitrite-mediated nitration [33]. As shown in Fig. 4, isoniazid and rifampicin inhibit in a dosedependent fashion the HSA-heme-Fe(III)-based protection of free L-tyrosine against peroxynitrite-mediated nitration in the absence and presence of $\mathrm{CO}_{2}$. In fact, the relative yield of nitro-L-tyrosine increases on increasing the isoniazid and rifampicin concentrations at fixed HSA-heme$\mathrm{Fe}(\mathrm{III})$, peroxynitrite, L-tyrosine, and $\mathrm{CO}_{2}$ concentrations.

According to Eq. 9 (Figs. 4, S3), the analysis of the dependence on the isoniazid and rifampicin concentrations of the relative yield of nitro-L-tyrosine formed from the reaction of peroxynitrite with free L-tyrosine $(Y)$ allowed the determination of the $\mathrm{CO}_{2}$-independent values of $K_{\mathrm{h}}$ for isoniazid and rifampicin binding to HSA-heme-Fe(III) $\left[(3.6 \pm 0.4) \times 10^{-3}\right.$ and $(1.7 \pm 0.2) \times 10^{-4} \mathrm{M}$, respectively, at $20.0^{\circ} \mathrm{C}$; and $(4.3 \pm 0.4) \times 10^{-3}$ and $(2.1 \pm 0.2) \times 10^{-4} \mathrm{M}$, respectively, at $37.0^{\circ} \mathrm{C}$. Under all the experimental conditions, the Hill coefficient $(n)$ for isoniazid and rifampicin binding to HSA-heme-Fe(III) ranges between $0.98 \pm 0.02$ and $1.01 \pm 0.02$, indicating that drug binding to HSA-heme$\mathrm{Fe}(\mathrm{III})$ is a noncooperative event. Note that the data obtained at $20.0{ }^{\circ} \mathrm{C}$ agree with those determined at $37.0^{\circ} \mathrm{C}$ (see Figs. 4, S3). Under conditions where the drug concentration is much greater than $K_{\mathrm{h}}$, HSA-heme-Fe(III) does not protect free L-tyrosine against peroxynitrite-mediated nitration.

As expected, the values of $K_{\mathrm{h}}$ obtained spectrophotometrically (Fig. 2) and from the dependence of $l_{\text {on }}$ on the isoniazid and rifampicin concentrations (Fig. 3) are in excellent agreement with those obtained from the dependence of the relative yield of nitro-L-tyrosine formed from the reaction of peroxynitrite with free L-tyrosine on the drug concentration (Figs. 4, S3). 
Table 1 Effect of the isoniazid and rifampicin concentrations on $l_{0}$ and $l_{\text {on }}$ values for ferric human serum heme-albumin [HSA-heme-Fe(III)]mediated peroxynitrite isomerization in the absence and presence of $\mathrm{CO}_{2}$ at $\mathrm{pH} 7.2$ and $20.0^{\circ} \mathrm{C}$

\begin{tabular}{|c|c|c|c|c|c|c|c|c|c|}
\hline \multirow[t]{2}{*}{ Isoniazid (M) } & \multicolumn{2}{|c|}{$l_{0}$ or $l_{0}^{\mathrm{d}}\left(\mathrm{s}^{-1}\right)^{\mathrm{a}}$} & \multicolumn{2}{|c|}{$l_{\mathrm{on}}$ or $l_{\mathrm{on}}^{\mathrm{d}}\left(\mathrm{M}^{-1} \mathrm{~s}^{-1}\right)$} & \multirow[t]{2}{*}{ Rifampicin (M) } & \multicolumn{2}{|c|}{$l_{0}$ or $l_{0}^{\mathrm{d}}\left(\mathrm{s}^{-1}\right)^{\mathrm{a}}$} & \multicolumn{2}{|c|}{$l_{\mathrm{on}}$ or $l_{\mathrm{on}}^{\mathrm{d}}\left(\mathrm{M}^{-1} \mathrm{~s}^{-1}\right)$} \\
\hline & $-\mathrm{CO}_{2}$ & $+\mathrm{CO}_{2}^{\mathrm{b}}$ & $-\mathrm{CO}_{2}$ & $+\mathrm{CO}_{2}^{\mathrm{b}}$ & & $-\mathrm{CO}_{2}$ & $+\mathrm{CO}_{2}^{\mathrm{b}}$ & $-\mathrm{CO}_{2}$ & $+\mathrm{CO}_{2}^{\mathrm{b}}$ \\
\hline \multirow[t]{2}{*}{$0.0^{\mathrm{c}}$} & $0.28^{\mathrm{c}}$ & $15.9^{\mathrm{c}}$ & $4.1 \times 10^{5 \mathrm{c}}$ & $4.3 \times 10^{5 c}$ & $0.0^{\mathrm{c}}$ & $0.28^{\mathrm{c}}$ & $15.9^{\mathrm{c}}$ & $4.1 \times 10^{5 c}$ & $4.3 \times 10^{5 c}$ \\
\hline & 0.26 & 16.3 & & & & 0.26 & 16.3 & & \\
\hline \multirow[t]{2}{*}{$2.0 \times 10^{-4}$} & 0.29 & 17.2 & $4.0 \times 10^{5}$ & $4.2 \times 10^{5}$ & $4.0 \times 10^{-5}$ & 0.29 & 17.2 & $3.6 \times 10^{5}$ & $3.4 \times 10^{5}$ \\
\hline & 0.31 & 15.9 & & & & 0.28 & 18.9 & & \\
\hline \multirow[t]{2}{*}{$4.0 \times 10^{-4}$} & 0.27 & 16.9 & $3.8 \times 10^{5}$ & $4.0 \times 10^{5}$ & $5.0 \times 10^{-5}$ & 0.27 & 16.9 & $3.1 \times 10^{5}$ & $3.3 \times 10^{5}$ \\
\hline & 0.25 & 18.4 & & & & 0.24 & 17.5 & & \\
\hline \multirow[t]{2}{*}{$8.0 \times 10^{-4}$} & 0.31 & 15.2 & $3.7 \times 10^{5}$ & $3.6 \times 10^{5}$ & $8.0 \times 10^{-5}$ & 0.31 & 15.2 & $2.7 \times 10^{5}$ & $2.6 \times 10^{5}$ \\
\hline & 0.28 & 16.9 & & & & 0.23 & 15.8 & & \\
\hline \multirow[t]{2}{*}{$1.5 \times 10^{-3}$} & 0.26 & 18.4 & $3.2 \times 10^{5}$ & $3.4 \times 10^{5}$ & $1.0 \times 10^{-4}$ & 0.26 & 18.4 & $2.3 \times 10^{5}$ & $2.5 \times 10^{5}$ \\
\hline & 0.27 & 16.3 & & & & 0.27 & 19.1 & & \\
\hline \multirow[t]{2}{*}{$3.0 \times 10^{-3}$} & 0.25 & 20.3 & $2.4 \times 10^{5}$ & $2.7 \times 10^{5}$ & $2.0 \times 10^{-4}$ & 0.25 & 20.3 & $1.7 \times 10^{5}$ & $1.5 \times 10^{5}$ \\
\hline & 0.28 & 18.4 & & & & 0.26 & 19.8 & & \\
\hline \multirow[t]{2}{*}{$5.0 \times 10^{-3}$} & 0.30 & 17.6 & $2.1 \times 10^{5}$ & $2.3 \times 10^{5}$ & $2.5 \times 10^{-4}$ & 0.30 & 17.6 & $1.3 \times 10^{5}$ & $1.5 \times 10^{5}$ \\
\hline & 0.27 & 16.5 & & & & 0.28 & 16.9 & & \\
\hline \multirow[t]{2}{*}{$7.5 \times 10^{-3}$} & 0.28 & 18.1 & $1.9 \times 10^{5}$ & $1.7 \times 10^{5}$ & $4.0 \times 10^{-4}$ & 0.28 & 18.1 & $1.3 \times 10^{5}$ & $1.1 \times 10^{5}$ \\
\hline & 0.26 & 19.3 & & & & 0.29 & 17.4 & & \\
\hline \multirow[t]{2}{*}{$1.0 \times 10^{-2}$} & 0.26 & 16.5 & $1.3 \times 10^{5}$ & $1.4 \times 10^{5}$ & $5.0 \times 10^{-4}$ & 0.26 & 16.5 & $1.1 \times 10^{5}$ & $1.0 \times 10^{5}$ \\
\hline & 0.27 & 18.8 & & & & 0.25 & 16.6 & & \\
\hline
\end{tabular}

${ }^{a}$ In regular style are shown values of $l_{0}$ and $l_{0}^{\mathrm{d}}$ for HSA-heme-Fe(III)-catalyzed peroxynitrite isomerization. In italics are shown values of $l_{0}$ and $l_{0}^{\mathrm{d}}$ for peroxynitrite isomerization obtained in the absence of HSA-heme-Fe(III)

b The $\mathrm{CO}_{2}$ concentration was $1.2 \times 10^{-3} \mathrm{M}$

${ }^{\mathrm{c}}$ Under conditions where the drug concentration is $0.0 \mathrm{M}, l_{0}=l_{0}^{\mathrm{d}}$, and $l_{\mathrm{on}}=l_{\mathrm{on}}^{\mathrm{d}}$

Table $2 \mathrm{NO}_{3}{ }^{-}$and $\mathrm{NO}_{2}{ }^{-}$distribution of peroxynitrite isomerization in the absence and presence of HSA-heme-Fe(III), $\mathrm{CO}$, isoniazid, and rifampicin at $\mathrm{pH} 7.2$ and $20.0^{\circ} \mathrm{C}$

\begin{tabular}{lllllrr}
\hline HSA-heme-Fe(III) $(\mathrm{M})$ & $\mathrm{CO}_{2}(\mathrm{M})$ & Isoniazid $(\mathrm{M})$ & Rifampicin $(\mathrm{M})$ & $\mathrm{NO}_{3}^{-}(\%)$ & $\mathrm{NO}_{2}^{-}(\%)$ & $\mathrm{NO}_{3}^{-}+\mathrm{NO}_{2}^{-}(\%)$ \\
\hline- & - & - & - & $74 \pm 5$ & $24 \pm 4$ & 98 \\
- & $1.2 \times 10^{-3}$ & - & - & $86 \pm 5$ & $15 \pm 3$ & 101 \\
- & - & $1.0 \times 10^{-2}$ & - & $77 \pm 5$ & $23 \pm 3$ & 100 \\
- & $1.2 \times 10^{-3}$ & $1.0 \times 10^{-2}$ & & $85 \pm 3$ & $15 \pm 3$ & 100 \\
- & - & - & $5.0 \times 10^{-4}$ & $73 \pm 5$ & $28 \pm 3$ & 101 \\
- & $1.2 \times 10^{-3}$ & - & $5.0 \times 10^{-4}$ & $84 \pm 8$ & $15 \pm 3$ & 99 \\
$5.0 \times 10^{-5}$ & - & - & $88 \pm 5$ & $13 \pm 3$ & 101 \\
$5.0 \times 10^{-5}$ & $1.2 \times 10^{-3}$ & - & - & $92 \pm 4$ & $7 \pm 3$ & 99 \\
$5.0 \times 10^{-5}$ & - & $1.0 \times 10^{-2}$ & & $91 \pm 5$ & $9 \pm 3$ & 100 \\
$5.0 \times 10^{-5}$ & $1.2 \times 10^{-3}$ & $1.0 \times 10^{-2}$ & & & $12 \pm 3$ & 101 \\
$5.0 \times 10^{-5}$ & - & - & $5.0 \times 10^{-4}$ & $92 \pm 3$ & $7 \pm 4$ & 99 \\
$5.0 \times 10^{-5}$ & $1.2 \times 10^{-3}$ & - & $5.0 \times 10^{-4}$ & $90 \pm 4$ & $12 \pm 3$ & 102 \\
\hline
\end{tabular}

\section{Automated docking simulation of isoniazid and rifampicin binding to HSA}

An automated docking analysis of isoniazid and rifampicin was performed in Sudlow's site I (FA7) of HSA to confirm that these drugs could easily bind to this site (Fig. 5).
Isoniazid, a small ligand, binds to the FA7 subchamber, where the coumarinic ring of warfarin is located, with an interaction energy of $-24.3 \mathrm{~kJ} \mathrm{~mol}^{-1}$, in agreement with that calculated from $K_{0}$. On the other hand, rifampicin only partially enters into Sudlow's site I opening that recognizes the benzyl group of warfarin. Therefore, this prevents the 

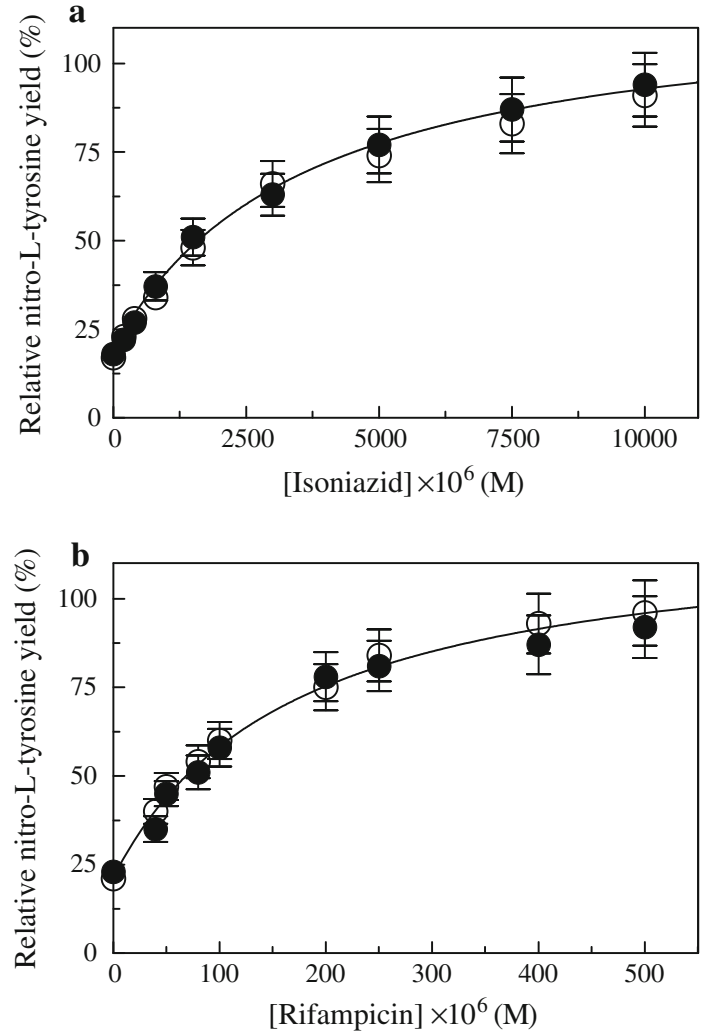

Fig. 4 Effect of isoniazid (a) and rifampicin (b) concentrations on the relative yield of nitro-L-tyrosine formed from the reaction of peroxynitrite with free L-tyrosine at $\mathrm{pH} 7.2$ and $20.0{ }^{\circ} \mathrm{C}$ in the presence of HSA-heme-Fe(III) and in the absence (open circles) and presence (filled circles) of $\mathrm{CO}_{2}$. The lines were calculated according to Eq. 9 with the following parameters: a $K_{\mathrm{h}}=(3.6 \pm 0.4) \times$ $10^{-3} \mathrm{M}$ and $R=19.3 \pm 1.7 \%$; and $\mathbf{b} K_{\mathrm{h}}=(1.7 \pm 0.2) \times 10^{-4} \mathrm{M}$ and $R=21.3 \pm 2.0 \%$. The concentrations of HSA-heme-Fe(III), peroxynitrite, free L-tyrosine, and $\mathrm{CO}_{2}$ were $2.5 \times 10^{-5}, 2.0 \times 10^{-3}$, $1.0 \times 10^{-4}$, and $1.2 \times 10^{-3} \mathrm{M}$, respectively. Where not shown, the standard deviation is smaller than the symbol. For details, see the text

determination of the rifampicin docking energy. It should be noticed, however, that the simulation does not take into account induced-fit conformational changes involving the protein backbone [64].

\section{Discussion}

Isoniazid and rifampicin bind noncooperatively to Sudlow's site I, as suggested by the drug-dependent quenching of the intrinsic HSA fluorescence [6, 21, 22, 57, 58, 69]. As expected for Sudlow's site I ligands, both antituberculosis drugs modulate allosterically heme-Fe(III) binding to HSA as well as peroxynitrite isomerization by HSA-heme$\mathrm{Fe}(\mathrm{III})$, highlighting the role of heterotropic ligands in modulating the HSA(-heme) reactivity [8, 32, 48, 72].

The affinity of isoniazid and rifampicin for HSA decreases by about 1 order of magnitude in the presence of saturating amounts of heme-Fe(III) (Fig. 2). Further, as expected on the basis of linked functions [45], the heme$\mathrm{Fe}(\mathrm{III})$ affinity for HSA decreases by about 1 order of magnitude in the presence of saturating amounts of isoniazid and rifampicin (Fig. 2). Accordingly, the difference in the reaction free energy for drug binding to HSA in the absence and presence of heme-Fe(III) $\left[\delta \Delta G^{\circ}=\right.$ $\left.-R T \ln \left(K_{0} / K_{\mathrm{h}}\right)=5.6 \pm 0.2 \mathrm{~kJ} \mathrm{~mol}^{-1}\right]$ is similar to the difference in the reaction free energy for heme-Fe(III) binding to HSA in the absence and presence of drugs $\left[\delta \Delta G^{\circ}=-R T \ln \left(H_{0} / H_{\mathrm{d}}\right)=5.8 \mathrm{~kJ} \mathrm{~mol}^{-1}\right]$ at $\mathrm{pH} 7.2$ and $20.0^{\circ} \mathrm{C}$. This value, which is essentially drug-independent $[8,9,21,22,26,34,38,69]$, indicates that the interaction energy between the Sudlow's site I and FA1, where the heme binds, is $5.7 \mathrm{~kJ} \mathrm{~mol}^{-1}$ independent of the affinity of the drug for Sudlow's site I; this value likely reflects the free energy associated with the conformational change(s) required for the structural communication between the two sites.

Peroxynitrite isomerization is facilitated by HSA-heme$\mathrm{Fe}(\mathrm{III})$ (see the present study and [33]). However, unlike ibuprofen inhibition of HSA-heme-Fe(III) action by binding to Sudlow's site II [33], isoniazid and rifampicin impair allosterically HSA-heme-Fe(III)-mediated peroxynitrite isomerization by binding to Sudlow's site I (Fig. 5). This behavior could reflect drug-dependent structural changes occurring at the heme binding pocket of HSA. Indeed, abacavir binding to Sudlow's site I modulates peroxynitrite-mediated oxidation of ferrous nitrosylated HSA-heme [HSA-heme-Fe(II)-NO] [48]. Moreover, abacavir binding and warfarin binding to Sudlow's site I facilitate HSAheme-Fe(II)-NO denitrosylation [31]. Both events reflect the drug-dependent neutral-to-basic conformational transition in HSA-heme-Fe(II)-NO [31, 48]. Sudlow's site I ligands interact with Tyr150 and Arg252 residues, two key residues positioned in the center of the drug binding site. In turn, Tyr150 drives the reorientation of Phe149, which is no longer available for the stabilization of the heme-Fe(III) porphyrin ring by $\pi-\pi$ stacking, with a consequent effect on the heme-Fe(III)-based catalysis (see the present study and $[9,31,33,48])$.

Peroxynitrite isomerization by heme-Fe(III) proteins [e.g., HSA-heme-Fe(III)] could represent a physiological detoxification mechanism, protecting cells from reactive nitrogen and oxygen species [70,71]; this potential role is reinforced by the evidence that enzymatically active HSAheme-Fe(III) indeed protects L-tyrosine from the nitrosylation (see Figs. 4, S3). Note that the rate of peroxynitrite isomerization by HSA-heme-Fe(III) is faster by about 1 order of magnitude than the rates reported for ferric horse heart myoglobin, sperm whale myoglobin, and human hemoglobin [33, 53, 59]. Moreover, peroxynitrite isomerization by HSA-heme-Fe(III) is faster than peroxynitrite 


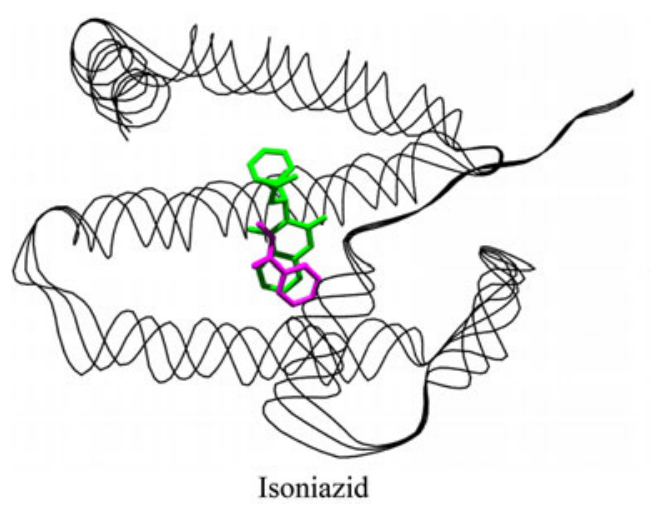

Fig. 5 Binding mode of isoniazid and rifampicin to the FA7 site of HSA. Isoniazid and rifampicin are rendered in magenta sticks. Warfarin, the prototypical ligand of the FA7 site (i.e., Sudlow's site I), is rendered in green sticks. Structural models have been obtained

scavenging by ferrous nitrosylated heme proteins, which appears to be strongly limited by (1) the dissociation of the heme-Fe(III)-NO transient and (2) the reduction of the final heme-Fe(III) species to the ferrous heme derivative $[33,48]$.

Owing to the role of HSA in human plasma [1-9], some in vivo implications could be argued from the present results:

1. Peroxynitrite isomerization by HSA-heme-Fe(III) could occur only in patients affected by diseases where a relevant intravascular hemolysis takes place. Under these pathological conditions, the HSA-heme-Fe(III) plasma level increases from the physiological concentration (approximately $1 \times 10^{-6} \mathrm{M}$ ) to approximately $4 \times 10^{-5} \mathrm{M}[20,73]$. To mimic as much as possible this condition, the HSA-heme-Fe(III) concentration here used ranged from $5.0 \times 10^{-6}$ to $5.0 \times 10^{-5} \mathrm{M}$.

2. Although the in vivo concentration of peroxynitrite is openly debated, the level of peroxynitrite in the reperfused ischemic heart has been reported to be much higher than micromolar concentration, at least over a brief period of time [70, 71], overlapping the lowest peroxynitrite concentration here used $\left(2.5 \times 10^{-5} \mathrm{M}\right)$.

3. Accounting for the plasma HSA concentration (approximately $7.5 \times 10^{-4} \mathrm{M}$ ) [2], the plasma levels of isoniazid and rifampicin (ranging between $1 \times 10^{-5}$ and $\left.1 \times 10^{-4} \mathrm{M}[74,75]\right)$, and the values of $K_{0}$ and $K_{\mathrm{h}}$ determined here, the molar fraction of the drug-bound HSA and HSA-heme-Fe(III) could range between 10 and $50 \%$.

Any inhibitory effect on peroxynitrite isomerization by HSA-heme-Fe(III) results in a relevant effect on the putative HSA detoxification role. The fact that several drugs binding at different sites of HSA might reduce this potentially important role should induce some caution for

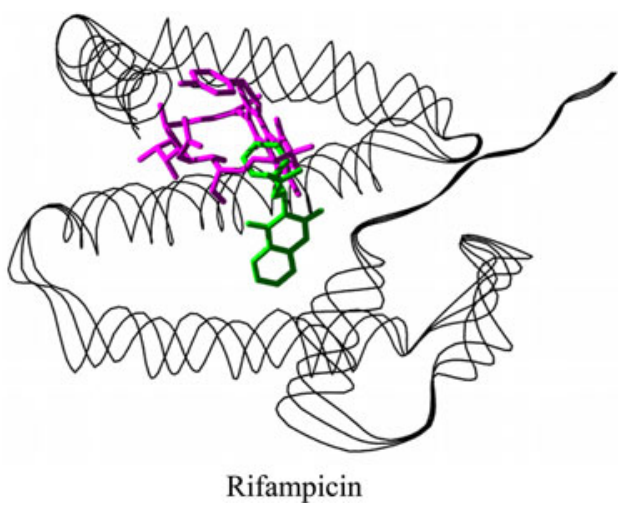

by simulation of automated docking of drugs into the FA7 binding cleft of the HSA structure (Protein Data Bank code 2BXD [7]). For details, see the text

the simultaneous drug administration employed for several therapeutic protocols. Thus, this control should be carried out routinely to avoid some paradoxical therapeutic effect, as for the management of antituberculosis therapy. Indeed, the increase of the plasma levels of heme-Fe(III) under pathological conditions $[20,72]$ may induce a release of antituberculosis drugs; accordingly, the toxic free-heme plasma concentration could increase in patients under antituberculosis drug therapy. Moreover, the protective role of HSA-heme-Fe(III), catalyzing peroxynitrite detoxification, could be impaired by antituberculosis drugs; this could facilitate the peroxynitrite-mediated nitration of aromatic residues (such as Tyr), which represents a relevant posttranslational protein modification process $[70,71,76]$.

Acknowledgments This work was partially supported by grants from the Ministero dell'Istruzione, dell'Università e della Ricerca of Italy (PRIN 2007ECX29E_002 and University Roma Tre, CLAR 2009, to P.A.) and from the Ministero della Salute of Italy (Istituto Nazionale per le Malattie Infettive I.R.C.C.S. 'Lazzaro Spallanzani', Ricerca corrente 2009 to P.A.).

\section{References}

1. Sudlow G, Birkett DJ, Wade DN (1975) Mol Pharmacol 11:824-832

2. Peters T Jr (ed) (1996) All about albumin: biochemistry, genetics and medical applications. Academic Press, San Diego

3. Curry S (2002) Vox Sang 83(Suppl 1):315-319

4. Kragh-Hansen U, Chuang VT, Otagiri M (2002) Biol Pharm Bull 25:695-704

5. Sakurai Y, Ma SF, Watanabe H, Yamaotsu N, Hirono S, Kurono Y, Kragh-Hansen U, Otagiri M (2004) Pharm Res 21:285-292

6. Sułkowska A, Bojko B, Równicka J, Sułkowski W (2004) Biopolymers 74:256-262

7. Ghuman J, Zunszain PA, Petitpas I, Bhattacharya AA, Otagiri M, Curry S (2005) J Mol Biol 353:38-52 
8. Ascenzi P, Bocedi A, Notari S, Fanali G, Fesce R, Fasano M (2006) Mini Rev Med Chem 6:483-489

9. Ascenzi P, Fasano M (2010) Biophys Chem 148:16-22

10. Curry S, Mandelkov H, Brick P, Franks N (1998) Nat Struct Biol 5:827-835

11. Sugio S, Kashima A, Mochizuki S, Noda M, Kobayashi K (1999) Protein Eng 12:439-446

12. Yamasaki K, Maruyama T, Yoshimoto K, Tsutsumi Y, Narazaki R, Fukuhara A, Kragh-Hansen U, Otagiri M (1999) Biochim Biophys Acta 1432:313-323

13. Bhattacharya AA, Curry S, Franks NP (2000) J Biol Chem 275:38731-38738

14. Bhattacharya AA, Grüne T, Curry S (2000) J Mol Biol 303:721-732

15. Petitpas I, Bhattacharya AA, Twine S, East M, Curry S (2001) J Biol Chem 276:22804-22809

16. Chuang VTG, Otagiri M (2002) Pharm Res 19:1458-1464

17. Hamilton JA (2004) Prog Lipid Res 43:177-199

18. Lejon S, Frick IM, Björck L, Wikström M, Svensson S (2004) J Biol Chem 279:42924-42928

19. Curry S (2009) Drug Metab Pharmacokinet 24:342-357

20. Miller YI, Shaklai N (1999) Biochim Biophys Acta 1454:153-164

21. Ascenzi P, Bocedi A, Notari S, Menegatti E, Fasano M (2005) Biochem Biophys Res Commun 334:481-486

22. Bocedi A, Notari S, Menegatti E, Fanali G, Fasano M, Ascenzi P (2005) FEBS J 272:6287-6296

23. Fasano M, Fanali G, Leboffe L, Ascenzi P (2007) IUBMB Life 59:436-440

24. Fasano M, Baroni S, Vannini A, Ascenzi P, Aime S (2001) J Biol Inorg Chem 6:650-658

25. Wardell M, Wang Z, Ho JX, Robert J, Rüker F, Ruble J, Carter DC (2002) Biochem Biophys Res Commun 291:813-819

26. Nicoletti FP, Howes BD, Fittipaldi M, Fanali G, Fasano M, Ascenzi P, Smulevich G (2008) J Am Chem Soc 130:11677-11688

27. Komatsu T, Matsukawa Y, Tsuchida E (2000) Bioconjug Chem $11: 772-776$

28. Monzani E, Bonafé B, Fallarini A, Redaelli C, Casella L, Minchiotti L, Galliano M (2001) Biochim Biophys Acta 1547:302-312

29. Kamal JK, Behere DV (2002) J Biol Inorg Chem 7:273-283

30. Komatsu T, Ohmichi N, Nakagawa A, Zunszain PA, Curry S, Tsuchida E (2005) J Am Chem Soc 127:15933-15942

31. Ascenzi P, Imperi F, Coletta M, Fasano M (2008) Biochem Biophys Res Commun 369:686-691

32. Fasano M, Fanali G, Fesce R, Ascenzi P (2008) In: Bolognesi M, di Prisco G, Verde C (eds) Dioxygen binding and sensing proteins. Springer, Heidelberg, pp 121-131

33. Ascenzi P, di Masi A, Coletta M, Ciaccio C, Fanali G, Nicoletti FP, Smulevich G, Fasano M (2009) J Biol Chem 284:31006-31017

34. Baroni S, Mattu M, Vannini A, Cipollone R, Aime S, Ascenzi P, Fasano M (2001) Eur J Biochem 268:6214-6220

35. Mattu M, Vannini A, Coletta M, Fasano M, Ascenzi P (2001) J Inorg Biochem 84:293-296

36. Fasano M, Mattu M, Coletta M, Ascenzi P (2002) J Inorg Biochem 91:487-490

37. Monzani E, Curto M, Galliano M, Minchiotti L, Aime S, Baroni S, Fasano M, Amoresano A, Salzano AM, Pucci P, Casella L (2002) Biophys J 83:2248-2258

38. Fanali G, Fesce R, Agrati C, Ascenzi P, Fasano M (2005) FEBS J 272:4672-4683

39. Fanali G, Bocedi A, Ascenzi P, Fasano M (2007) FEBS J 274:4491-4502

40. Fanali G, De Sanctis G, Gioia M, Coletta M, Ascenzi P, Fasano M (2009) J Biol Inorg Chem 14:209-217

41. Fanali G, Pariani G, Ascenzi P, Fasano M (2009) FEBS J 276:2241-2250
42. Kragh-Hansen U, Watanabe H, Nakajou K, Iwao Y, Otagiri M (2006) J Mol Biol 363:702-712

43. Simard JR, Zunszain PA, Hamilton JA, Curry S (2006) J Mol Biol 361:336-351

44. du Toit LC, Pillay V, Danckwerts MP (2006) Respir Res 7:118

45. Wyman J Jr (1964) Adv Protein Chem 19:223-286

46. Kharitonov VG, Sharma VS, Magde D, Koesling D (1997) Biochemistry 36:6814-6818

47. Boffi A, Das TK, Della Longa S, Spagnolo C, Rousseau DL (1999) Biophys J 77:1143-1149

48. Ascenzi P, Fasano M (2007) Biochem Biophys Res Commun 353:469-474

49. Notari S, Mancone C, Sergi M, Gullotta F, Bevilacqua N, Tempestilli M, Urso R, Lauria FN, Pucillo LP, Tripodi M, Ascenzi P (2010) IUBMB Life 62:387-393

50. Bohle DS, Glassbrenner PA, Hansert B (1996) Methods Enzymol 269:302-311

51. Koppenol WH, Kissner R, Beckman JS (1996) Methods Enzymol 269:296-302

52. Herold S, Exner M, Boccini F (2003) Chem Res Toxicol 16:390-402

53. Herold S, Kalinga S, Matsui T, Watanabe Y (2004) J Am Chem Soc 126:6945-6955

54. Ascenzi P, Visca P (2008) Methods Enzymol 436:317-337

55. Goldstein S, Merényi G (2008) Methods Enzymol 436:49-61

56. Goldstein S, Lind J, Merényi G (2005) Chem Rev 105:2457-2470

57. Bocedi A, Notari S, Narciso P, Bolli A, Fasano M, Ascenzi P (2004) IUBMB Life 56:609-614

58. Yang JD, Deng SX, Liu ZF, Kong L, Liu SP (2007) Luminescence 22:559-566

59. Herold S, Kalinga S (2003) Biochemistry 42:14036-14046

60. Herold S, Matsui T, Watanabe Y (2001) J Am Chem Soc 123:4085-4086

61. Miranda KM, Espey MG, Wink DA (2001) Nitric Oxide 5:62-71

62. Ascenzi P, Bocedi A, Bolognesi M, Fabozzi G, Milani M, Visca P (2006) Biochem Biophys Res Commun 339:450-456

63. Goodsell DS, Olson AJ (1990) Proteins 8:195-202

64. Goodsell DS, Morris GM, Olson AJ (1998) J Mol Recogn 9:1-5

65. Morris GM, Goodsell DS, Halliday RS, Huey R, Hart WE, Belew RK, Olson AJ (1998) J Comput Chem 19:1639-1662

66. Metcalfe C, Macdonald IK, Murphy EJ, Brown KA, Raven EL, Moody PC (2008) J Biol Chem 283:6193-6200

67. Campbell EA, Korzheva N, Mustaev A, Murakami K, Nair S, Goldfarb A, Darst SA (2001) Cell 104:901-912

68. Maes V, Engelborghs Y, Hoebeke J, Maras Y, Vercruysse A (1982) Mol Pharmacol 21:100-107

69. Fanali G, Rampoldi V, di Masi A, Bolli A, Lopiano L, Ascenzi P, Fasano M (2010) IUBMB Life 62:371-376

70. Herold S, Fago A (2005) Comp Biochem Physiol A Mol Integr Physiol 142:124-129

71. Ascenzi P, di Masi A, Sciorati C, Clementi E (2010) Biofactors 36:264-273

72. Fasano M, Curry S, Terreno E, Galliano M, Fanali G, Narciso P, Notari S, Ascenzi P (2005) IUBMB Life 57:787-796

73. Muller-Eberhard U, Javid J, Liem HH, Hanstein A, Hanna M (1968) Blood 32:811-815

74. Houin G, Beucler A, Richelet S, Brioude R, Lafaix C, Tillement JP (1983) Ther Drug Monit 5:67-72

75. Delahunty T, Lee B, Conte JE (1998) J Chromatogr B Biomed Sci Appl 705:323-329

76. Alvarez B, Radi R (2003) Amino Acids 25:295-311

77. Pfeiffer S, Gorren AC, Schmidt K, Werner ER, Hansert B, Bohle DS, Mayer B (1997) J Biol Chem 272:3465-3470

78. Zunszain PA, Ghuman J, Komatsu T, Tsuchida E, Curry S (2003) BMC Struct Biol 3:6 